\title{
Application Strategy of Mechatronics in Mechanical Design and Manufacturing
}

\author{
Zhe Lin*, Rongqing Fang \\ Zhejiang Dahua Technology Co., Ltd., Hangzhou 310051, Zhejiang Province, China
}

\begin{abstract}
Industry is an pillar sector for our country's social and economic development. The development of industry is closely related to our country's economic development and social construction. The application of mechatronics in mechanical design and manufacturing can not only improve the level of mechanical design and manufacturing as well as production efficiency, but also can contribute to the further development of the mechanical design and manufacturing industry. The author investigated and analyzed advantages of the mechatronics's application in mechanical design and manufacturing, and put forward an effective strategy of applying mechatronics in mechanical design and manufacturing, hoping to help strengthen the comprehensive strength of the mechanical design and manufacturing industry.
\end{abstract}

Keywords: Mechanical design; Mechatronics; Application strategy

Publication date: May, 2021; Publication online: 31 May, 2021

*Corresponding author: Zhe Lin, lin_zhe@dahuatech.com

\section{Introduction}

Mechanical design and manufacturing is a new type of advanced technical means, breaking some limitations of manual control of mechanical equipment in the past. It not only reduces the loss of human resources, but also accurately locates the development direction of the mechanical design and manufacturing industry from a macro perspective, and further improves and optimizes the mechanical design and manufacturing system. For this reason, mechanical design and manufacturing enterprises should fully realize the important advantages of applying mechatronics technology in the process of operation and development, and strengthen the application of this technology, so as to further promote the development of the enterprise.

2 Important advantages of mechatronics applications in mechanical design and manufacturing

Mechatronics is a new concept proposed in the field of industrial sector. The application of mechatronics design and manufacture of products has better performance. Compared with the previous industrial production technology, mechatronics technology has greater application advantages in mechanical design and manufacturing. (Table 1)

Table 1. Important application advantages of mechatronics

\begin{tabular}{|l|l|}
\hline \multicolumn{1}{|c|}{ Advantages of mechatronics } & \multicolumn{1}{c|}{ Specifically in } \\
\hline Its production is safer and more reliable. & $\begin{array}{l}\text { 1. Mechatronics technology integrates computer technology and electronic } \\
\text { information system technology, which can automatically monitor the } \\
\text { production line and self-check for failures. Once a failure occurs, it will } \\
\text { automatically cut off the power for protection. } \\
2 . \text { Mechatronics is very sensitive to changes in current and voltage, so it } \\
\text { has a high level of safety in production. When the equipment current is } \\
\text { abnormal or overloaded, the equipment will automatically power off and }\end{array}$ \\
\hline
\end{tabular}




\begin{tabular}{|l|l|}
\hline & $\begin{array}{l}\text { issue an alarm to avoid damage to important electronic components. } \\
\text { 3. Using circuit control and program design, the equipment can be } \\
\text { operated with emergency stop settings. }\end{array}$ \\
\hline Its production capacity is better. & $\begin{array}{l}\text { 1. The emergence of mechatronics technology indicates that the } \\
\text { production technology in our country has entered the stage of automated } \\
\text { production. } \\
\text { 2. After entering the information in the system program, it will convert the } \\
\text { entered electrical signals into mechanical production capacity. Its } \\
\text { production capacity is quite good and can basically meet the } \\
\text { ever-expanding market demand. } \\
\text { 3. Mechatronics technology has enhanced information recognition and } \\
\text { input capabilities, which can automatically detect product information and } \\
\text { realize intelligent production. } \\
\text { 4. The application of mechatronics can minimize the interference to } \\
\text { production caused by manual operation and produce uninterruptedly. }\end{array}$ \\
$\begin{array}{ll}\text { 1. Mechatronics technology is operated by computer, using program } \\
\text { control and digital display to reasonably reduce the requirements for } \\
\text { operators. } \\
\text { Its maneuverability is stronger. } \\
\text { the pre-set degree, and the production synergy is high. } \\
\text { 3. Mechatronics equipment is highly intensive, and its own self-checking } \\
\text { system can handle some failures that occur during the operation of the } \\
\text { equipment by itself. }\end{array}$ \\
\hline
\end{tabular}

\section{Effective strategies for the application of} mechatronics in mechanical design and manufacturing

\subsection{Pay attention to improving the accuracy of machinery manufacturing}

The application of mechatronics in the field of machinery manufacturing must pay attention to improving the accuracy of mechanical design. Mechanical products have relatively high requirements for accuracy. In the production of mechanical products, if the corresponding parameters do not meet the design requirements, it will seriously affect the performance of the product itself, which will bring greater losses to the mechanical design enterprise. The use of information technology to replace previous manual operations can control the accuracy of mechanical products from a more microscopic perspective.

For example, mechanical cutting is an indispensable link in mechanical design. In the process of cutting machinery, in order to ensure the accuracy of cutting, a sensor can be used, which has many parts. And for different parts, the nature of production is also different. In the past, in the process of mechanical design, the staff used manual control to control the production quality of parts, but the accuracy of this control method is not very high. The sensor has a sensitive slewing system, temperature system and driving system, which can incorporate all survival parameters into the cutting machine system, so as to automatically control the machine equipment, prevent errors caused by manual operation, and optimize the performance of the cutting machine equipment ${ }^{[1]}$.

\subsection{Application of mechatronics in the monitoring system}

The application of mechatronics in the mechanical design monitoring system can not only improve the accuracy of mechanical design, production and manufacturing, but also supervise the mechanical production work, so that the staff can understand and grasp the operating status of the mechanical equipment in a timely manner. Once the mechanical equipment fails, the monitoring system will transmit the fault information to the operator in the first time, so that the operator can deal with the hidden trouble in time, so as to minimize the adverse effects and losses caused by 
the failure ${ }^{[2]}$. The monitoring system is an indispensable key link in the mechanical design. The problems that can be improved by the application of mechatronics in the monitoring system are shown in Table 2.

Table 2. Problems that can be improved by the application of mechatronics in the monitoring system

\begin{tabular}{|l|l|}
\hline \multicolumn{1}{|c|}{$\begin{array}{c}\text { Problems that can be improved by } \\
\text { mechatronics }\end{array}$} & \multicolumn{1}{c|}{ Specifically in } \\
\hline $\begin{array}{l}\text { Enhance the performance of the monitoring } \\
\text { system }\end{array}$ & $\begin{array}{l}\text { It can further improve the automatic inspection and automatic alarm } \\
\text { functions of the monitoring system. It is only necessary to input the } \\
\text { instructions in advance in the calculation to improve the } \\
\text { informationization, standardization and efficiency of mechanical work. }\end{array}$ \\
\hline Early warning & $\begin{array}{l}\text { When a system in the mechanical equipment fails during operation, the } \\
\text { monitoring system will quickly give an early warning, promptly } \\
\text { troubleshoot the faults in the system, and help the staff solve the problem } \\
\text { in time, thereby ensuring the smooth operation of the equipment. }\end{array}$ \\
\hline
\end{tabular}

\subsection{Application of mechatronics in numerical} control design

At present, the numerical control design industrial processing system has been developed relatively mature, and the application of mechatronics in numerical control design can further improve the modernization level of the system. The emergence of mechatronics is obviously an innovation for numerical control design. It can not only make up for the many shortcomings in the previous numerical control design, but also has a good role in promoting the development of it and processing industry. At this stage, the engines used in our country's industrial production are generally turbine engines or piston engines. These two types of engines are widely used, so the market demand for them is relatively large. At this stage, the urban turbine engine independently researched and developed in our country is becoming more and more mature, and both power and displacement have been significantly improved. This means that the engine production technology in our country has begun to mature, but the thermal efficiency of the engine still has a lot of room for improvement. Therefore, when applying mechatronics in numerical control design, computer drawing technology and CAD technology can be used to further optimize numerical control technology ${ }^{[3]}$.

\subsection{Application of mechatronics in power design}

Compared with the previous decentralized mechanical design, the application of mechatronics in power design can not only greatly provide mechanical manufacturing kinetic energy, but also reduce energy consumption. With the rapid development of social economy, the demand for internal combustion engines in our country is increasing. If we want to meet market demand, we need to increase the production kinetic energy of the machinery manufacturing industry and enhance productivity. The use of mechatronics can realize efficient control of the numerically-controlled machine tools. In the process of mechanical design in the past, hydraulic presses were usually chosen as an important source of power. However, the efficiency of hydraulic press is generally not very good. During the operation of the equipment, it will consume a lot of energy and cause serious waste ${ }^{[4]}$. The electronic governor is added to the mechanical hydraulic device, which can not only adjust and control the mechanical pressure, but also regulate the mechanical power

\section{The development prospect of the application}

\section{of mechatronics in mechanical design}

Table 3. Development prospects of mechatronics

\begin{tabular}{|c|l|}
\hline The development prospects of mechatronics & \multicolumn{1}{c|}{ Specifically in } \\
\hline intelligent & $\begin{array}{l}\text { Mechatronics is a new type of technology developed based on computer } \\
\text { technology and big data technology, which can promote the development } \\
\text { of mechatronics in a more intelligent direction. }\end{array}$ \\
\hline miniaturization & $\begin{array}{l}\text { The research and development of mechatronics smart chip technology } \\
\text { continues to improve, and it begins to develop in the direction of }\end{array}$ \\
\hline
\end{tabular}




\begin{tabular}{|l|l|}
\hline & miniaturization, and the accuracy is getting higher and higher. \\
\hline networked & $\begin{array}{l}\text { It uses the network platform to remotely control related workshops and } \\
\text { equipment to build an unmanned production workshop. }\end{array}$ \\
\hline
\end{tabular}

\section{References}

\section{Conclusion}

In summary, the application of mechatronics in mechanical design has important advantages that cannot be disregarded. It not only makes mechanical production safer and more reliable, but also promotes production capacity to become more excellent, and it also has stronger controllability. Therefore, it is necessary to strengthen the application of mechatronics in mechanical design, and promote the continuous development of mechatronics in the direction of intelligence, miniaturization and networking.
[1] Liu YL, Kou YJ. Development and Application of Mechatronics Technology in Intelligent Manufacturing[J]. Science and Technology Wind, 2021(17): 6-7.

[2] Jia HC. Exploring the application of mechatronics technology in intelligent manufacturing [J]. Agricultural Equipment Technology, 2021, 47(03): 60-61.

[3] Li M. Integrated design analysis of automatic control technology for electromechanical control system [J]. Electronic Technology and Software Engineering, 2021(10): 108-109.

[4] Lu SS. Research on fault diagnosis technology of mechatronics equipment $[\mathrm{J}]$. Times Automobile, 2021(09):177-178 